\title{
Exercise addiction and its related factors in amateur runners
}

\author{
ANDREA LUKÁCS ${ }^{1 *}$, PÉTER SASVÁRI $^{2,3}$, BEATRIX VARGA $^{4}$ and KRISZTINA MAYER ${ }^{1}$ \\ ${ }^{1}$ Faculty of Health Care, University of Miskolc, Miskolc, Hungary \\ ${ }^{2}$ Faculty of Mechanical Engineering and Informatics, University of Miskolc, Miskolc, Hungary \\ ${ }^{3}$ Faculty of Science of Public Governance and Administration, National University of Public Service, Budapest, Hungary \\ ${ }^{4}$ Faculty of Economics, University of Miskolc, Miskolc, Hungary
}

(Received: June 24, 2018; revised manuscript received: October 12, 2018; second revised manuscript received: January 31, 2019; third revised manuscript received: April 27, 2019; accepted: April 27, 2019)

\begin{abstract}
Background and aims: This study examines exercise addiction (EA) in amateur runners from a multidimensional approach, including demographics (age, sex, educational attainment, and financial situation), training factors (duration of running activity, weekly time spent running, mean workout distance per session, other sports activities, and childhood physical activity), psychological features (perceived health, life satisfaction, loneliness, stress, anxiety, depression, body shape, and eating disorders), and anthropometrics (body mass index) that might predict EA. Methods: The well-validated Exercise Dependence Scale (EDS) was applied to evaluate the prevalence of EA in amateur runners. A multinomial logistic regression was performed to find explanatory variables of risk of EA using the SPSS 24.0 statistical software. Results: A total of 257 runners ( $48.9 \%$ females, $M_{\text {age }}=40.49, S D=8.99$ years) with at least 2 years running activity participated in an anonymous questionnaire survey. About $53.6 \%$ of respondents were characterized as non-dependent symptomatic and $37.8 \%$ as non-dependent asymptomatic. About $8.6 \%$ had prevalence of being at risk of EA. The logistic regression model displayed five variables that significantly predicted the risk of EA: (a) anxiety, (b) loneliness, (c) weekly time spent running, (d) childhood physical activity, and (e) education level. Discussion and conclusions: Findings indicate that loneliness and anxiety may lead to withdrawal and uncontrolled behavior that in turn leads to increased amount of exercise in amateur runners. Lower level of education attainment is also a likely risk of EA development, and childhood sports activity is a predictor.
\end{abstract}

Keywords: exercise addiction, amateur runners, loneliness, anxiety, time spent running

\section{INTRODUCTION}

Running is the most convenient way to exercise intensely. People can improve their mental and physical health, as well as their physical fitness. Running even a few minutes per day is associated with reduced risks of cardiovascular disease (Lee et al., 2014). To attain beneficial physiological adaptation, exercisers have to practice regularly. It appears that higher amounts of physical activity provide greater health benefits (O'Donovan et al., 2010); however, there is no consensus on the upper limits of intensity, frequency, and duration to exercise in an optimal way. In recent decades, a new behavioral addiction called "Exercise Addiction" (EA) has been observed when exercisers overtrain and consequently suffer severe withdrawal symptoms if they cannot exercise (Landolfi, 2013). Increasing workout or training times often ignores fatigue and also increases the risk of sometimes irreversible physical injuries. Although evidence of EA exists, it is not referenced in the latest (fifth) edition of the Diagnostic and Statistical Manual of Mental Disorders (American Psychiatric Association [APA], 2013). Its criteria are not well established, appropriate studies in the field are lacking, and incidence of EA is currently understood to be rare (Szabo, Griffiths, de La Vega Marcos, Mervó, \& Demetrovics, 2015).

The number of amateur exercisers is increasing year by year. Some become so involved with the sports activity they are doing that the exercise slowly becomes compulsive; they feel an irresistible impulse to continue exercising, despite personal affects like fatigue, injury, or illness (Hausenblas \& Downs, 2002a; Johnson, 2000). It is not fully evident how to distinguish normal amounts of exercise from excessive exercise. Hausenblas and Downs (2002b) developed a screening scale based on a modification of the criteria for substance dependence. If an individual shows three or more of the indicators (such as tolerance, withdrawal, lack of control, intention effect, time, reduction in other activities, and continuance), there is cause for concern. This psychometric instrument is widely used in research studies and has been validated in several countries. In this study, we use the

\footnotetext{
* Corresponding author: Assoc. Prof. Andrea Lukács, PhD; Faculty of Health Care, University of Miskolc, 3515 MiskolcEgyetemváros, Hungary; Phone: +36 46565111 ext. 2215; Fax: +36 46 366961; E-mails: lukacs.andrea@ymail.com; lukacs. andrea@uni-miskolc.hu
}

This is an open-access article distributed under the terms of the Creative Commons Attribution-NonCommercial 4.0 International License, which permits unrestricted use, distribution, and reproduction in any medium for non-commercial purposes, provided the original author and source are credited, a link to the CC License is provided, and changes - if any - are indicated. 
term addiction instead of terms such as "dependence," "compulsive," "excessive," "obligatory," or "exercise abuse," as they elude to the same phenomenon (Berczik et al., 2012; Szabo, 2010; Szabo et al., 2015).

EA is very complex and its emergence is still not yet clearly determined. It can manifest as a primary symptom (when EA is the main problem) or it can be a secondary symptom where EA develops as a consequence of the primary problem of an individual, for example, eating disorders, body image disorders, or weight control dysfunction (Freimuth, Moniz, \& Kim, 2011; Zmijewski \& Howard, 2003). Generally, regular exercise has a positive impact on an individual's mental health, but in its addictive form, it is often associated with psychological distress (Lichtenstein, Nielsen, Gudex, Hinze, \& Jørgensen, 2018) and sociocultural factors (Adams \& Kirkby, 2002; Demetrovics \& Kurimay, 2008). Kotbagi, Morvan, Romo, and Kern (2017) indicated that EA can serve as a short-term coping strategy to relieve negative affective states or to avoid negative emotions. We assume that people who are feeling isolated and lonely are looking for activities that can give them pleasure. Running is a sport activity that can be executed alone or in groups, but individuals suffering from loneliness (perceived social isolation or possibly lack of social reward) are more prone to unhealthy behaviors, presumably including unhealthy exercise behavior.

When evaluating the risk of EA, it is essential to measure the exercise characteristics. To date, there are still insufficient studies that assess the association between being at risk of EA in amateur runners and key parameters, such as number of years spent running activity, time spent training a week, workout distance, historical sports activity (past positive experience with exercise), and demographic and psychological factors. Therefore, studying risk of EA and its related factors from a multidimensional perspective in amateur runners can provide more insights to this behavioral problem. Amateur runners are considered as those who engage in running as a recreational activity and are not involved in international professional sports (although taking part in competitions was not an excluding factor). The main objective of this study is to find the prevalence of risk of EA and the effect of exercise characteristics, demographics, and psychological features on the probability of being at risk of EA.

\section{METHODS}

\section{Participants and procedure}

Participants were contacted via two Hungarian community websites for runners ("cross-country race" and "running mates") during a 2-month period in the summer of 2017. They received an e-mail invitation with access to an online questionnaire. All responses were anonymous and no personally identifiable information was requested. The inclusion criteria were: (a) to be at least 18 years of age, (b) physically active for at least 2 years in running on an amateur level, and (c) not an active athlete of the Hungarian National Athletics Association. The questionnaire took approximately 25-30 min to complete.

\section{Measures}

Demographics. Demographic items captured participants' sex, age, educational level, and financial situation.

Exercising activity. Participants reported how long they had been running and how much time they spent running per week. Total weekly training time was categorized in intervals of $1-2,3-4,5-7,8-10$, and $>10 \mathrm{hr}$. Participants indicated their mean workout distance per session, childhood physical activity, and whether they were engaged in other sports activities.

Exercise addiction (EA). It was measured using the Exercise Dependence Scale - Revised (Hausenblas \& Downs, 2002b). The authors revised the factorial structure of the original 42-item scale into 21 items (Downs, Hausenblas, \& Nigg, 2004). These items were rated on a 6-point Likert scale ranging from 1 (never) to 6 (always), with three items per subscale (i.e., seven factors or subscales). A higher score indicates more exercise dependent symptoms. The scale allows both interval data and nominal categorization. For categorization, a scoring syntax file was developed by the authors. Individuals scoring 5 or 6 out of the seven DSM-IV criteria (tolerance, withdrawal effects, intention, lack of control, reduction in other activities, time, and continuance) were classified as at risk of EA, whereas those scoring in the range of 3-4 were classified as nondependent symptomatic, and scores of 1-2 are categorized as non-dependent asymptomatic. The Exercise Dependence Scale - Revised has a psychometrically validated Hungarian version (Mónok et al., 2012). Its psychometric properties are: $\quad \chi^{2}=351.9, \quad d f=168, \quad p<.0001 ; \quad$ CFI $=0.938$; $\mathrm{TLI}=0.922 ;$ RMSEA $=0.049$ [0.042-0.056]; Cfit $=0.590$; SRMR = 0.052). In our work, we used this version of the scale. In this study, the internal consistency of the scale was determined with Cronbach's $\alpha(\alpha=.903)$.

Overall life satisfaction. It was evaluated with the Cantril ladder on a scale of 1-10, where 1 represented the worst possible life satisfaction and 10 described the best (Cantril, 1965). It measured how satisfied the individuals were with their life as a whole.

Eating disorders. These were screened using the 5-item SCOFF questionnaire ( $\mathrm{S}=$ sick, $\mathrm{C}=$ control, $\mathrm{O}=$ one stone, $\mathrm{F}=$ fat, $\mathrm{F}=$ food) One point was assigned for every "yes" response. A score greater than two indicated a possible case of anorexia, bulimia nervosa, or binge eating (Morgan, Reid, \& Lacey, 1999). The questionnaire was adapted for Hungarian usage (Dukay-Szabó et al., 2016). The internal consistency of the short questionnaire was adequate in our sample $(\alpha=.702)$

Loneliness. The UCLA 3-item Loneliness Scale was applied to evaluate runners' loneliness. This scale comprised three questions that measured three dimensions of loneliness: relational connectedness, social connectedness, and self-perceived isolation. The scale used three response categories: (a) hardly ever, (b) some of the time, and (c) often. Scores were summed and a higher score indicated more loneliness (Hughes, Waite, Hawkley, \& Cacioppo, 2004). The internal consistency of the inventory was good in our sample $(\alpha=.845)$.

Body shape concerns. Body Image Subscale was used from the Body Investment Scale to evaluate the participants' 
feelings and attitudes toward their body (Orbach \& Mikulincer, 1998). The six items are on a 5-point Likert scale and range from 1 (I do not agree at all) to 5 (I strongly agree). Mean scores were calculated and higher scores indicated more positive views of the body. The scale was adapted for Hungarian usage (Czeglédi, Urbán, \& Csizmadia, 2010). The internal consistency of scale was good in our sample $(\alpha=.922)$.

Emotional profile. Depression, anxiety, and stress were evaluated using the DASS-21, which quantifies distress along the dimensions of depression (seven items), anxiety (seven items), and stress (seven items; Lovibond \& Lovibond, 1995). Respondents indicated on a 4-point scale the extent to which each of 21 statements applied over the previous week with 0 (did not apply at all) to 3 (applied very much or most of the time). Higher scores on each subscale indicated increasing severity of depression, anxiety, or stress. The internal consistency of subscales in our sample was $\alpha=$ between .736 and .888 .

Anthropometry. Body mass index (BMI) was calculated from self-reported height and weight according to the Adolphe Quetelet formula: body weight $(\mathrm{kg}) /$ height $\left(\mathrm{m}^{2}\right)$.

\section{Statistical analyses}

Statistical Package for the Social Sciences (IBM SPSS Statistics, version 24.0 for Windows, Armonk, NY, USA) was used for data analyses. Significance level was set at $p \leq .05$. Descriptive statistics (percentages, frequencies, means, and standard deviations) were used to present all variables. Cronbach's $\alpha$ s were calculated to determine internal consistency of scales used in the study. A multinomial logistic regression analysis was performed to find explanatory variables of risk of EA.

\section{Variables in the model}

Dependent variables measured exercise dependence symptoms on three levels: non-dependent asymptomatic, nondependent symptomatic, and at risk of EA.

Independent variables included categorical (gender, educational level, financial situation, childhood physical activity, eating disorders, and other sports activity besides running) and continuous variables (age, BMI, duration of running activity, weekly time spent running, mean workout distance per session, body image, perceived health, life satisfaction, loneliness, stress, anxiety, and depression).

Analysis of variance (ANOVA) with Tukey's post hoc test was performed to find differences among three groups in subscales and items of Exercise Dependence Scale (EDS).

\section{Ethics}

The Regional Ethic Committee and the institutional review board of the University of Miskolc approved the study. According to the criteria of the Helsinki Declaration on Consent to Research and Clinical Practice, information was provided to participants about the study, its anonymity, and the voluntary nature of the participation at the beginning of the questionnaire. Participants were then required to provide their consent (trough click), which acknowledged that they had read and understood the information and agreed to take part in the study.

\section{RESULTS}

\section{Participants' characteristics}

A total of 285 runners completed the questionnaire. Five were incomplete and thus deleted, 16 runners did not meet the criteria of having exercised for at least 2 years or provided no data about it. Two were less than 18 years of age, and an additional five were eliminated due to BMI below 17.5 (which is the diagnostic criterion for anorexia nervosa; APA, 2013). If an eating disorder is detected, the EA may be a secondary condition. Respondents represented all geographical and economic parts of the country. Demographic data are presented in Table 1.

\section{Prevalence of risk of EA in amateur runners}

The prevalence of risk of EA was $8.6 \%$, whereas $53.6 \%$ of respondents were characterized non-dependent symptomatic and $37.8 \%$ non-dependent asymptomatic.

\section{Predicting the likelihood of categorization for EA}

A multinomial logistic regression was employed to analyze the association between the polychotomous categorical (EA group classification, such as non-dependent asymptomatic, non-dependent symptomatic, and at risk group for EA) and a set of explanatory variables. The reference category for the outcome variable was "non-dependent asymptomatic" and each of the other two categories was compared to this reference group. The logistic model was statistically

Table 1. Descriptive statistics of the participants

\begin{tabular}{lc}
\hline Mean $(S D)$ and frequency & Participants \\
\hline Sample size & 257 \\
Age (years) & $40.49(8.99)$ \\
BMI & $23.89(3.28)$ \\
Sex ratio (\%) & $51.1: 48.9$ \\
$\quad$ Male:female & \\
Socioeconomic background (\%) & $5.2: 77.7: 17.2$ \\
$\quad$ Below average:average:above & \\
$\quad$ average & $0: 38.2: 61.8$ \\
Educational attainment (\%) & \\
$\quad$ Elementary:high school:higher & \\
$\quad$ education & \\
Weekly amount of training sessions (\%) & \\
$\quad$ 1-2:3-4:5-7:8-10:10+ hr & $13.18(12.42)$ \\
$\quad$ Running activity (years) & \\
Other sport activities besides running (\%) & \\
$\quad$ Yes:No & $70.8: 29.2$ \\
Childhood physical activity (\%) & \\
$\quad$ Yes:no & $50.2: 49.8$ \\
\hline
\end{tabular}

Note. SD: standard deviation.

${ }^{a}$ Yes: to be engaged in regular sports; no: not to be engaged in regular sports. 
significant, $\chi^{2}(36)=193.38, p<.001$. The distribution of Cox and Snell $R^{2}(.358)$ and Nagelkerke $R^{2}(.427)$ suggests that between $35.8 \%$ and $42.6 \%$ of the variance is explained by the set of variables used in this model and $68.7 \%$ of cases were correctly classified. The likelihood ratio tests indicated that five factors (weekly time spent running, childhood physical activity, educational attainment, anxiety, and loneliness) contributed meaningfully to the full effect (Table 2).

\section{Participants' attitude toward running}

The analysis of the subscales of EDS suggested that runners from all groups found it important to continually increase exercise intensity, frequency, and duration [Tolerance subscale $(3.71, S D=1.28,95 \% \mathrm{CI}=3.55-3.87)]$ and to spend a significant amount of time engaging in exercise [Time subscale (3.09, $S D=1.11,95 \% \mathrm{CI}=2.96-3.23])$. We observed that the at risk group scored higher on the Lack of Control subscale $(4.90, S D=0.76,95 \% \mathrm{CI}=4.57-5.23)$ and therefore these runners were less able to control the urge to exercise or to stop exercising for a significant time. All investigated groups showed fewer problems on the Intention subscale (exercising longer than intended, expected, or planned; 2.39, $S D=1.10,95 \% \quad \mathrm{CI}=2.25-2.52)$ and the Reduction in Other Activities subscale (choosing or thinking about exercise rather than spending time with family, friends, or concentrating on school or work; 1.90 , $S D=0.82,95 \% \mathrm{CI}=1.80-2.00)$.
The ANOVA with Tukey's post hoc test revealed that all three groups significantly differed from each other in all subscales (Table 3 ) and in almost all items except Item 2 (I exercise despite recurring physical problems) and 19 (I choose to exercise so that I can get out of spending time with family/friends) between symptomatic and at risk groups.

\section{DISCUSSION}

In this study, amateur runners were assessed based on a validated and widely used multidimensional scale, that is, the EDS categorization. The prevalence of runners at risk of EA was moderate $(8.6 \%)$ in this study. The result provides some evidence that this problem exists, but to date it is not as extensive as other behavioral addictions (Sussman, Lisha, \& Griffiths, 2011). The prevalence rate is greatly varied across the studies (Egorov \& Szabo, 2013) and this discrepancy might possibly be related to both different questionnaires being used in the studies (Weik \& Hale, 2009) and to the differences in the investigated populations, such as students (Sicilia, Alías-García, Ferriz, \& Moreno-Murcia, 2013), competitive athletes (Blaydon \& Lindner, 2002), or recreational exercisers (MayolasPi et al., 2017). Population-based studies showed a very low prevalence of $0.09 \%-0.30 \%$ in the general population (Mónok et al., 2012; Müller et al., 2013). In this study, we focused specifically on the physically active adult

Table 2. Multinomial logistic regression predicting likelihood of exercise addiction $(N=257)$

\begin{tabular}{|c|c|c|c|c|c|}
\hline \multirow{2}{*}{$\begin{array}{l}\text { For at risk group } \\
\text { Variables }\end{array}$} & \multirow[b]{2}{*}{$B(S E)$} & \multicolumn{3}{|c|}{$95 \% \mathrm{CI}$ for $\mathrm{OR}$} & \multirow[b]{2}{*}{$p$} \\
\hline & & Lower & OR & Upper & \\
\hline Duration of weekly training session & $1.43(0.39)$ & 1.93 & 4.17 & 8.99 & $<.001$ \\
\hline Childhood sport activity $(1)^{\mathrm{a}}$ & $2.06(0.78)$ & 1.71 & 7.86 & 36.20 & .008 \\
\hline Educational level $(3)^{\mathrm{b}}$ & $1.97(0.72)$ & 1.76 & 7.17 & 29.26 & .006 \\
\hline Anxiety & $0.47(0.21)$ & 1.07 & 1.61 & 2.42 & .023 \\
\hline Loneliness & $0.79(0.27)$ & 1.29 & 2.21 & 3.78 & .004 \\
\hline
\end{tabular}

Note. SE: standard error; CI: confidence interval; OR: odds ratio.

${ }^{a}$ Childhood sport activity: (1): to be engaged in regular sports. ${ }^{b}$ Educational level: (3): higher education (college or university degree).

Table 3. One-way ANOVA for EDS subscales

\begin{tabular}{|c|c|c|c|c|c|c|c|c|c|c|c|}
\hline \multirow[b]{4}{*}{ Subscales } & \multirow{2}{*}{\multicolumn{3}{|c|}{$\frac{\text { Non-dependent asymptomatic }}{n=97}$}} & \multirow{2}{*}{\multicolumn{3}{|c|}{$\frac{\text { Non-dependent symptomatic }}{n=137}$}} & \multirow{2}{*}{\multicolumn{3}{|c|}{$\frac{\text { At risk of exercise addiction }}{n=23}$}} & \multirow[b]{4}{*}{$F$ test } & \multirow[b]{4}{*}{$\eta_{p}^{2}$} \\
\hline & & & & & & & & & & & \\
\hline & \multirow[b]{2}{*}{$M(S D)$} & \multicolumn{2}{|c|}{$95 \%$ CI } & \multirow[b]{2}{*}{$M(S D)$} & \multicolumn{2}{|c|}{$95 \%$ CI } & \multirow[b]{2}{*}{$M(S D)$} & \multicolumn{2}{|c|}{$95 \%$ CI } & & \\
\hline & & L & U & & $\mathrm{L}$ & $\mathrm{U}$ & & L & U & & \\
\hline To & $2.83(1.14)$ & 2.61 & 3.06 & $4.11(1.01)$ & 3.94 & 4.28 & $5.06(0.88)$ & 4.68 & 5.44 & $63.053 *$ & .365 \\
\hline $\mathrm{Ti}$ & $2.43(0.86)$ & 2.26 & 2.61 & $3.29(0.94)$ & 3.13 & 3.45 & $4.74(0.79)$ & 4.40 & 5.08 & $68.147^{*}$ & .371 \\
\hline $\mathrm{C}$ & $2.21(1.04)$ & 2.00 & 2.42 & $3.22(1.12)$ & 3.03 & 3.41 & $4.28(1.41)$ & 3.67 & 4.88 & $41.578^{*}$ & .304 \\
\hline $\mathrm{L}$ & $1.86(0.72)$ & 1.71 & 2.00 & $3.11(0.80)$ & 2.98 & 3.24 & $4.90(0.76)$ & 4.57 & 5.23 & $171.509 *$ & .587 \\
\hline W & $2.03(0.98)$ & 1.83 & 2.22 & $3.00(1.31)$ & 2.78 & 3.22 & $4.00(1.48)$ & 3.36 & 4.64 & $32.757^{*}$ & .222 \\
\hline I & $1.73(0.71)$ & 1.59 & 1.87 & $2.59(0.94)$ & 2.43 & 2.75 & $3.92(1.33)$ & 3.34 & 4.50 & $61.963 *$ & .360 \\
\hline $\mathrm{R}$ & $1.39(0.40)$ & 1.31 & 1.47 & $2.08(0.74)$ & 1.96 & 2.21 & $3.01(1.03)$ & 2.57 & 3.46 & $65.249^{*}$ & .386 \\
\hline
\end{tabular}

Note. To: Tolerance; Ti: Time; C: Continuance; L: Lack of Control; W: Withdrawal; I: Intention Effect; R: Reduction; $M$ : mean; SD: standard deviation; L: lower bound; U: upper bound; EDS: Exercise Dependence Scale; ANOVA: analysis of variance; CI: confidence interval. $* p<.001$. 
population with at least 2 years of prior running activity. All participants were amateur runners and the male to female ratio was well-balanced in our sample.

The etiology of EA is undoubtedly multifactorial. In this study, psychological aspects (anxiety and loneliness), exercise characteristics (time spent training and childhood physical activity), as well as a demographic factor (educational level) regressed EA.

It is well known that EA can cause psychological distress. Exercisers often feel anxiety when they cannot exercise for any reason. In addition to anxiety, we found loneliness as an explanatory variable. It should not be surprising that athletes generally run alone and find this privacy pleasurable, but being alone does not necessarily mean being lonely (Presumably, personality traits have an impact on the type of sport activity the person chooses.). A systematic review was uncertain about the relationship between physical activity and loneliness. On one hand, it found that physical activity can contribute to a decrease in loneliness and on the other hand there was some evidence that physical inactivity may lead to feelings of loneliness over time (Pels \& Kleinert, 2016). As sports psychology literature on loneliness is scarce, future research is needed to understand the influence of loneliness the development of risk of EA. Although Menczel (2016) did not evaluate the loneliness factor, she observed that athletes exercising alone show more symptoms of EA than those involved in team sports. However, another study failed to disclose differences in EA between individual and team exercisers (Kovacsik, Soós, de la Vega, Ruíz-Barquín, \& Szabo, 2018). Logically, our findings support the theory that lonely exercisers use the sport activity as a source of joyfulness and happiness. To deal with both anxiety and loneliness, exercisers increase the time or volume of sport activity as they need more and more to achieve this feeling. It is noteworthy that exercising excessively is not necessarily maladaptive. Elite athletes perform their training with great volume and intensity, but are not at risk of EA. If they were, they would not be able to compete at a high level. Thus, the results of the instrument used among elite athletes (Szabo et al., 2015) must be interpreted with caution when considering amateur athletes. We think this sport-specific factor should be taken into consideration in future investigation of amateur/recreational runners evaluating the risk for EA.

One interesting and novel finding is that childhood engagement in sport activity predicts the likelihood of EA. The health benefits of regular physical activity are well established and it is also well known that childhood physical activity has benefits in later life (Janssen \& LeBlanc, 2010) and predicts adult physical activity (Telama et al., 2005). The effect of childhood engagement in sport activity on EA needs deeper research. A theoretical approach to this relationship may include the adolescent population (both girls and boys), which may also show symptoms of EA. Downs, Savage, and DiNallo (2013) found that the majority of physically active youth was within the symptomatic range suggesting that many adolescents show early signs of exercise pathology that can lead to the development of EA later in life among the physically active population.

In our adult sample, all had high-school education and a majority $(\sim 60 \%)$ had completed their higher education degree. Lower education level is a predictor of EA. It is likely that studying at universities or colleges improves skills to deal with emotional distress and coping mechanisms, which in turn can prevent behavioral disturbance and presumably several other problems (Menczel, 2016).

There are some limitations in this study that must be acknowledged. Our survey is voluntary and response-based. The self-report EDS provides risk score and at risk categorization and not a clinical diagnosis. Although participants are from different parts of Hungary, representing all geographical and economic regions, non-respondents might differ from the respondents, which can limit the generalizability of the findings. Childhood physical activity, one of our predictors, is measured with a single item instead of a validated scale. It is supposed that a single-item measure can be used and is appropriate when the construct is narrow and unambiguous to the respondents (Carsrude \& Brännback, 2014). Because of the cross-sectional design of this study, we cannot establish either the direction or the causality of the effects.

\section{CONCLUSIONS AND IMPLICATIONS}

The present findings add to the studies that focus on risk of EA using multidimensional approach in amateur athletes. Physical activity recommendations and guidelines indicate that a high volume of physical activity needs to be performed every day for school-aged children and young adults (Janssen \& LeBlanc, 2010). Given that regular physical exercise has several health benefits, it seems controversial that higher amounts of weekly workout and childhood sports activity predict EA. While examining risk of EA, it is important to consider the possible comorbidities and psychosocial problems of the individual. It is supposed that inactive youth will likely remain inactive in adulthood; they will not be engaged in sport activity in later life and never will face risk of EA. As long as the main public health concern is the physical inactivity, the guidelines will not focus on rare behavioral problems such as EA. Anxiety and loneliness are two other predictors of EA important to consider. Loneliness is a predictor of anxiety. Both feelings of loneliness and isolation are a cause and a symptom of anxiety (Muyan et al., 2016). Lonely individuals try to reduce their anxiety with sport (Phillips, Kiernanm, \& King, 2003) and spending time by themselves. Running seems to be an optimal sport for them, but they may need more and more workouts to feel better. Future investigations should extend to other types of sports to examine these findings.

Risk of EA occurs among amateur runners, but research studies have contradictory findings as it relates to influencing and predicting factors, presumably due to the varying methods and investigated populations. To date, it is difficult to give unequivocal answers to the real reasons of the development of risk of EA. For prevention and treatment of this phenomenon, a methodologically well-established and longitudinal research program should address the issue. Nonetheless, we believe that our multidimensional research study contributes to the overall knowledge related to EA. 
Funding sources: No financial support was received for this study.

Authors' contribution: AL and KM drafted the manuscript, contributed in study concept and design, and wrote the manuscript. KM, PS, and BV were involved in data collection. LA and BV conducted the statistical analysis. All authors discussed the results and contributed to the final version of the manuscript.

Conflict of interest: The authors declare no conflict of interest.

Acknowledgements: The study was carried out as part of the EFOP-3.6.1-16-00011 "Younger and Renewing University Innovative Knowledge City - institutional development of the University of Miskolc aiming at intelligent specialisation" project implemented in the framework of the Szechenyi 2020 program. The realization of this project is supported by the European Union, co-financed by the European Social Fund.

\section{REFERENCES}

Adams, J., \& Kirkby, R. J. (2002). Excessive exercise as addiction: A review. Addiction Research and Theory, 10, 415-437. doi:10.1080/1606635021000032366

American Psychiatric Association [APA]. (2013). Diagnostic and statistical manual of mental disorders (5th ed.). Washington, DC: American Psychiatric Association.

Berczik, K., Szabo, A., Griffiths, M. D., Kurimay, T., Kun, B., Urbán, R., \& Demetrovics, Z. (2012). Exercise addiction: Symptoms, diagnosis, epidemiology, and etiology. Substance Use \& Misuse, 47(4), 403-417. doi:10.3109/10826084. 2011.639120

Blaydon, M. J., \& Lindner, K. J. (2002). Eating disorders and exercise dependence in triathletes. Eating Disorders, 10(1), 49-60. doi:10.1080/106402602753573559

Cantril, H. (1965). The pattern of human concern. New Brunswick, NJ: Rutgers University Press.

Carsrud, A. L., \& Brännback, M. (Eds.). (2014). Handbook of research methods and applications in entrepreneurship and small business. Northampton, MA: Edward Elgar Publishing.

Czeglédi, E., Urbán, R., \& Csizmadia, P. (2010). Measuring body image: Psychometric properties and construct validity of the Hungarian version of Body Attitude Test. Magyar Pszichológiai Szemle, 65(3), 431-461. doi:10.1556/MPSzle.65. 2010.3.1

Demetrovics, Z., \& Kurimay, T. (2008). Exercise addiction: A literature review. Psychiatria Hungarica, 23, 129-141. [article in Hungarian]

Downs, D. S., Hausenblas, H. A., \& Nigg, C. R. (2004). Factorial validity and psychometric examination of the Exercise Dependence Scale-Revised. Measurement in Physical Education and Exercise Science, 8(4), 183-201. doi:10.1207/s15327841 mpee0804_1
Downs, D. S., Savage, J. S., \& DiNallo, J. M. (2013). Selfdetermined to exercise? Leisure-time exercise behavior, exercise motivation, and exercise dependence in youth. Journal of Physical Activity and Health, 10(2), 176-184. doi:10.1123/ jpah.10.2.176

Dukay-Szabó, S., Simon, D., Varga, M., Szabó, P., Túry, F., \& Rathner, G. (2016). Hungarian adaptation of a Short Eating Disorders Scale (SCOFF). Ideggyógyászati Szemle, 69, 3-4. doi:10.18071/isz.69.E014

Egorov, A. Y., \& Szabo, A. (2013). The exercise paradox: An interactional model for a clearer conceptualization of exercise addiction. Journal of Behavioral Addictions, 2(4), 199-208. doi:10.1556/JBA.2.2013.4.2

Freimuth, M., Moniz, S., \& Kim, S. R. (2011). Clarifying exercise addiction: Differential diagnosis, co-occurring disorders, and phases of addiction. International Journal of Environmental Research and Public Health, 8(10), 4069-4081. doi:10.3390/ ijerph8104069

Hausenblas, H. A., \& Downs, D. S. (2002a). Exercise dependence: A systematic review. Psychology of Sport and Exercise, 3(2), 89-123. doi:10.1016/S1469-0292(00)00015-7

Hausenblas, H. A., \& Downs, D. S. (2002b). How much is too much? The development and validation of the Exercise Dependence Scale. Psychology and Health, 17(4), 387-404. doi:10.1080/0887044022000004894

Hughes, M. E., Waite, L. J., Hawkley, L. C., \& Cacioppo, J. T. (2004). A short scale for measuring loneliness in large surveys results from two population-based studies. Research on Aging, 26(6), 655-672. doi:10.1177/0164027504268574

Janssen, J., \& LeBlanc, A. G. (2010). Systematic review of the health benefits of physical activity and fitness in school-aged children and youth. International Journal of Behavioral Nutrition and Physical Activity, 7(1), 40. doi:10.1186/14795868-7-40

Johnson, M. (2000). Understanding exercise addiction. New York, NY: The Rosen Publishing Group.

Kotbagi, G., Morvan, Y., Romo, L., \& Kern, L. (2017). Which dimensions of impulsivity are related to problematic practice of physical exercise? Journal of Behavioral Addictions, 6(2), 221-228. doi:10.1556/2006.6.2017.024.

Kovacsik, R., Soós, I., de la Vega, R., Ruíz-Barquín, R., \& Szabo, A. (2018). Passion and exercise addiction: Healthier profiles in team than in individual sports. International Journal of Sport and Exercise Psychology. Advance online publication. doi:10.1080/1612197X.2018.1486873

Landolfi, E. (2013). Exercise addiction. Sports Medicine, 43(2), 111-119. doi:10.1007/s40279-012-0013-x

Lee, D. C., Pate, R. R., Lavie, C.J., Sui, X., Church, T. S., \& Blair, S. N. (2014). Leisure-time running reduces all-cause and cardiovascular mortality risk. Journal of the American College of Cardiology, 64(5), 472-481. doi:10.1016/j.jacc.2014. 04.058

Lichtenstein, M. B., Nielsen, R. O., Gudex, C., Hinze, C. J., \& Jørgensen, U. (2018). Exercise addiction is associated with emotional distress in injured and non-injured regular exercisers. Addictive Behaviors Reports, 8, 33-39. doi:10.1016/ j.abrep.2018.06.001

Lovibond, S. H., \& Lovibond, P. F. (1995). Manual for the Depression Anxiety Stress Scales (2nd ed.). Sydney, Australia: Psychology Foundation. 
Mayolas-Pi, C., Simón-Grima, J., Peñarrubia-Lozano, C., MunguíaIzquierdo, D., Moliner-Urdiales, D., \& Legaz-Arrese, A. (2017). Exercise addiction risk and health in male and female amateur endurance cyclists. Journal of Behavioral Addictions, 6(1), 74-83. doi:10.1556/2006.6.2017.018

Menczel, Z. (2016). The behavioral and psychological context of exercise dependence (Doctoral dissertation). Semmelweis University, Budapest.

Mónok, K., Berczik, K., Urbán, R., Szabo, A., Griffiths, M. D., Farkas, J., Magia, A., Eisingera, A., Kurimayf, T., Kökönyeia, G., Kuna, B., Paksig, B., \& Demetrovics, Z. (2012). Psychometric properties and concurrent validity of two exercise addiction measures: A population wide study. Psychology of Sport \& Exercise, 13(6), 739-746. doi:10.1016/j.psychsport. 2012.06.003

Morgan, J. F., Reid, F., \& Lacey, J. H. (1999). The SCOFF Questionnaire: Assessment of a new screening tool for eating disorders. British Medical Journal, 319(7223), 1467-1468. doi:10.1136/bmj.319.7223.1467

Muyan, M., Chang, E. C., Jilani, Z., Yu, T., Lin, J., \& Hirsch, J. K. (2016). Loneliness and negative affective conditions in adults: Is there any room for hope in predicting anxiety and depressive symptoms? The Journal of Psychology: Interdisciplinary and Applied, 150(3), 333-341. doi:10.1080/00223980.2015. 1039474

Müller, A., Claes, L., Smits, D., Gefeller, O., Hilbert, A., Herberg, A., Müller, V., Hofmeister, D., \& de Zwaan, M. (2013). Validation of the German version of the Exercise Dependence Scale. European Journal of Psychological Assessment, 29(3), 213-219. doi:10.1027/1015-5759/a000144

O'Donovan, G., Blazevich, A. J., Boreham, C., Cooper, A. R., Crank, H., Ekelund, U., Fox, K. R., Gately, P., Giles-Corti, B., Gill, J. M., Hamer, M., McDermott, I., Murphy, M., Mutrie, N., Reilly, J. J., Saxton, J. M., \& Stamatakis, E. (2010). The $\mathrm{ABC}$ of physical activity for health: A consensus statement from the British Association of Sport and Exercise Sciences. Journal of Sports Sciences, 28, 573-591. doi:10.1080/0264041 1003671212
Orbach, I., \& Mikulincer, M. (1998). The Body Investment Scale: Construction and validation of a Body Experience Scale. Psychological Assessment, 10(4), 415-425. doi:10.1037/ 1040-3590.10.4.415

Pels, F., \& Kleinert, J. (2016). Loneliness and physical activity: A systematic review. International Review of Sport and Exercise Psychology, 9(1), 231-260. doi:10.1080/1750984X.2016. 1177849

Phillips, W. T., Kiernanm, M., \& King, A. C. (2003). Physical activity as a nonpharmacological treatment for depression: A review. Journal of Evidence-Based Complementary and Alternative Medicine, 8(2), 139-152. doi:10.1177/10761675 02250792

Sicilia, Á., Alías-García, A., Ferriz, R., \& Moreno-Murcia, J. A. (2013). Spanish adaptation and validation of the Exercise Addiction Inventory (EAI). Psicothema, 25, 377-383. doi:10. 7334/psicothema2013.21

Sussman, S., Lisha, N., \& Griffiths, M. (2011). Prevalence of the addictions: A problem of the majority or the minority? Evaluation \& the Health Professions, 34(1), 3-56. doi:10.1177/ 0163278710380124

Szabo, A. (2010). Addiction to exercise: A symptom or a disorder? New York, NY: Nova Science Publishers.

Szabo, A., Griffiths, M. D., de La Vega Marcos, R., Mervó, B., \& Demetrovics, Zs. (2015). Methodological and conceptual limitations in exercise addiction research. The Yale Journal of Biology and Medicine, 88, 303-308.

Telama, R., Yang, X., Viikari, J., Välimäki, I., Wanne, O., \& Raitakari, O. (2005). Physical activity from childhood to adulthood: A 21-year tracking study. American Journal of Preventive Medicine, 28(3), 267-273. doi:10.1016/j.amepre. 2004.12.003

Weik, M., \& Hale, B. D. (2009). Contrasting gender differences on two measures of exercise dependence. British Journal of Sport Medicine, 43(3), 204-207. doi:10.1136/bjsm.2007.045138

Zmijewski, C. F., \& Howard, M. O. (2003). Exercise dependence and attitudes toward eating among young adults. Eating Behaviors, 4(2), 181-195. doi:10.1016/S1471-0153(03)00022-9 